\title{
LA VIRTUALIDAD: EL \\ NUEVO ESPACIO Y TIEMPO \\ DE ENCUENTRO ENTRE LAS \\ CIENCIAS HUMANAS Y LA TECNOLOGÍA
}

\author{
Ana Patricia Noguera \\ Carlos Yánez Canal \\ César Contreras \\ Eduardo Villegas \\ Guillermo D'braccio \\ Julián García \\ Luz Arabany Ramírez
}

1. La teoría de los dos mundos ${ }^{15}$ como una mirada crítica a la escisión entre lo real y lo virtual

En la cultura occidental, esta escisión tiene su origen en la idea platónica de la existencia de dos mundos:

Esta teoría ha sido desarrollada en investigaciones filosoficas-ambientales sobre la escisión entre naturaleza y cultura, naturaleza y sociedad. 
el mundo de las ideas, o sea de lo real, y el mundo de las apariencias, o sea el mundo de lo que se nos aparece, que es este mundo tangible y terrenal, material y degenerativo, este mundo en movimiento (Noguera, 2003).

La herencia judeocristiana y platónica hizo que la cultura occidental se construyera sobre la especie de estructura dual, que fue el soporte tanto de las relaciones de dominio y explotación inmisericorde de las tramas de la vida llamadas "naturaleza", como también de una mirada reduccionista y maniquea del concepto de realidad. Durante toda la historia del cristianismo occidental esta escisión llevó a que el concepto de realidad se le diera a lo celeste, a lo divino, gracias a la lectura realizada por los filosóficos cristianos, de Platón.

En la modernidad, el concepto de realidad viró hacia lo terrenal, el aquí y el ahora, la naturaleza y la vida social, gracias a la interpretación que los filósofos de la escolástica y luego algunos artistas del Renacimiento, hicieran de la filosofía aristotélica, interpretación que llevó a colocar lo real en el lugar en el que Platón había colocado lo aparente. Esta se centró, como cultura en la materialidad, en su explotación, en su valoración técnica y como recurso de la especie humana.

Sin embargo, en el reduccionismo tanto el concepto de realidad, como el de las prácticas humanas, continuaron presentes hasta hace varias décadas, cuando otra dimensión de realidad, la virtual, apareció de forma muy contundente, en escena.

Un neoplatonismo hizo su aparición también. Comenzó el viraje de la cultura hacia la realidad virtual, abandonando muchas de las prácticas corporales y carnales, para introducirse en el mundo de las pantallas. Pero esta realidad virtual entraba a las casas de todos nosotros, tenía su sitio en nuestra habitación y comenzaba a revolucionar el 
tiempo y el espacio: esa realidad eran la radio y la televisión.

No era que en culturas diferentes a la nuestra o en anteriores épocas históricas de occidente, no hubiera existido la realidad virtual. Lo virtual como un ámbito de la imaginación creadora, hace parte de la aiesthesis humana. La imaginación desborda la realidad material, carnal y corporal, y constituye otras formas de la realidad del arte, los sueños y la realidad teórica, realidades que en adelante llamamos virtuales.

Entonces la virtualidad ha existido siempre, se actualiza en hechos o sucesos, herramientas, objetos, formas de comunicación, esquemas de relación, como también maneras de hacer las cosas. La historia del hombre es constante virtualización de la sociedad en la que vive. Desde esta perspectiva la educación ha sido también virtual y se ha manifestado a través de artefactos, lugares y horarios que permiten la relación de conocimientos, profesores y la conexión entre una realidad y otra, es precisamente eso: que ambas gozan de la misma constitución. Ambas son realidad. Son manifestaciones de la permanente creatividad humana (son construcciones de la conciencia y de la inteligencia). Surgen de la naturaleza como formas de ser, como espíritu, como mente (Bateson, 1993). Están en la memoria de la vida desde hace millones de años, la una como concreción, la otra como posibilidad.

La virtualización y la actualización son grados opuestos de una naturaleza similar, y para que exista una de ellas debe existir la otra, pero "no al mismo tiempo, ni en el mismo espacio".

Para Aristóteles virtus significa potencia, posibilidad de ser; por ello la palabra virtud encarna características que el ser humano puede desarrollar, gracias a un ethos cultural. 
El cristianismo asumió este concepto y lo permeó de doctrina en cuanto a que las virtudes se redujeron a siete, que se oponían a los siete pecados más graves llamados pecados capitales.

La realidad viene de rex o sustancia, que tiene dos formas de ser escindidas en occidente: la rex pensante o sea la razón y la rex extensa o sea el cuerpo, la materialidad. Con Descartes esta escisión se realiza plenamente, para dar paso al predominio de la razón sobre el cuerpo y sobre la materialidad. Con la paulatina desacralización del mundo, surgida de la misma modernidad, el concepto de virtud queda relegado a los vestigios del ámbito religioso, por lo que se impone por así decirlo, un concepto de realidad que atiende más a las necesidades y exigencias económicas, políticas y sociales de la cultura burguesa altamente libertaria.

La modernidad burguesa marginó entonces aquellas figuras menospreciadas, o miradas como fuente de engaño por las figuras dominantes de poder, ya fueran religiosas o tecnocientíficas. Si la terrenalidad y la carnalidad habían sido vistas como fuente de pecado por el judaísmo y el cristianismo, cómo podrían considerarse el cuerpo y las estructuras de la vida terrenal, sino, y en el mejor de los casos, como medio de un conocimiento más elevado y auténtico, trascendental al mismo cuerpo y a las mismas estructuras de la vida terrenal, que sería el conocimiento científico, y en tanto que dicho cuerpo y dichas estructuras mundovitales de lo terreno, pudieran constituir fuentes más elevadas del conocimiento.

La entrada de la Modernidad en la teoría como un segundo comienzo, ya que el primero se había dado con Platón, fue la entrada en un mundo virtual, el de la ciencia, donde su matematización creó una constelación de ideas y verdades que se abrogaron el derecho a ser lo único real. El 
reduccionismo cientificista se movió pendularmente, de lo virtual a lo corporal o carnal, pero nunca aceptó que lo uno fuera una nueva forma de lo otro, ni viceversa.

\section{La teoría de la integración: Spinoza}

Sin embargo, cuando se habla de virtualidad, pareciera como si esta dimensión de la realidad, fuera una novedad aparecida en el seno de los desarrollos tecnológicos acaecidos durante el siglo XX. Es común pensar que la virtualidad se opone a la realidad y que ella perjudica el contacto que el ser humano pueda tener con otros seres humanos, pues es también común incluso entre académicos y profesores destacados, la idea de que la virtualidad no permite una comunicación completa y escinde al ser humano de su cotidianidad, de sus contextos y de su realidad.

Se desarrollan conceptos a partir del uso de las Tecnologías de Información y Comunicación como herramientas para dar soporte a los procesos de virtualización y actualización. Es en el ciberespacio, constituido a partir de Internet, que se favorecen las conexiones de los individuos y la aparición de sinergias; su característica de contexto (ambiente) vivo (cambiante) parece compartirse de una mejor manera, y los grupos que hacen uso de él tienen acceso a herramientas que les permiten orientarse en conjunto por intereses o competencias.

Como los intelectuales europeos del siglo XVIII leen a Spinoza, inmediatamente lo marginan, porque él está proponiendo en su Ética, que no existen dos sustancias sino una sola. No es posible entender al hombre fuera de la naturaleza, sino enteramente dentro de ella, como sustancia que se crea y se recrea a sí misma. Para Spinoza, "la libertad no es simplemente libertad de pensamiento, sino expansividad del cuerpo, su fuerza de conservación y reproducción 
en tanto que "multitudo". Es la multitudo que se constituye en sociedad con todas sus necesidades" (Negri, A. 1993, p. 333). La libertad spinoziana no es ruptura con la naturaleza, sino expansión creciente de la misma a través del cuerpo que en relación con el alma, plantea Spinoza en su Ética: "No solo entendemos que el alma humana está unida al cuerpo, sino también lo que debe entenderse por unión de alma y cuerpo. Sin embargo, nadie podrá entenderla adecuadamente, o sea, distintamente, si no conoce primero adecuadamente la naturaleza de nuestro cuerpo" (Spinoza, 1975 en Negri, 1993, p. 125).

El conocimiento del cuerpo según Spinoza, implica el conocimiento de la naturaleza de la cual somos co-sustanciales. Nuestros actos son actos de, en y para nuestro cuerpo-naturaleza. Esta propuesta es totalmente contraria a la propuesta kantiana (1972), que separa radicalmente la ética de toda determinación de la naturaleza, porque para Kant la ética se basa en máximas universales, que trascienden el espacio-tiempo de la geografía, la cultura, las diferencias étnicas y las condiciones sociales.

El pensamiento de Spinoza en su Ethica, muestra la crisis de una forma interesante. Spinoza según Negri, quiere romper, ir más allá de las oposiciones paradojales entre cuerpo y alma, o entre pensamiento y afectos, entre la sustancia pensante y la sustancia extensa, entre lo real como naturaleza, como materialidad, y lo virtual como potencia. Spinoza quiere disolver estas contradicciones, en una continuidad, en una integralidad no dialéctica, sino ontológica. Sin ninguna mediación. "Lo que aquí (en la Ethica) comienza a configurarse como crisis es la convergencia espontánea de las dos tensiones: pero todo ello se da de una manera vaga y no expresamente percibida, casi a despecho de la voluntad sistemática" (p. 119). La relación entre sustancia y modo, es el problema fundamental de Spinoza. "El 
mundo es paradoja de diversidad y conciencia: sustancia y modo se rompen la una sobre el otro y viceversa" (pp. 119 y 120 ).

Para Spinoza en su Ethica, el orden y la conexión con las ideas, es lo mismo que el orden y la conexión con el mundo. No hay dos acontecimientos diferentes que se encuentren mediatizados por un concepto, sino que mundo y Dios, Dios y Razón son lo mismo que se diversifica, se singulariza, se ramifica. "La potencia salvaje de la naturaleza spinozista es, como siempre, el primer escenario del proyecto constitutivo. El derecho natural es, entonces, la ley misma de la naturaleza en su inmediación" (Negri, p. 320).

La naturaleza virtual es a la vez expresión y potenciación. Esta potencia es el desenvolvimiento del cuerpo. No hay una separación entre lo que tiene lugar, o es y lo que aún no ha tenido lugar: utopía.

Para Lévy las cosas solo tienen límites establecidos en lo real, la virtualidad es un continuo paso entre el interior y lo exterior de un mismo objeto, la identidad de los mismos es juzgada y ya no hay excluidos ni incluidos en los sitios y en los momentos. Los elementos que la conforman no se pueden establecer con precisión, están dispersos y no hay pertenencia a una posición.

Según la lectura que Negri hace de Spinoza, "...una praxis constitutiva forma la desutopía. La desutopía es la representación teórica de la determinabilidad, de la fenomenología de la praxis: desutopía como determinación como actualidad determinada" (...). "El ser está maduro para la libertad. La libertad y la felicidad se construyen, por tanto, como manifestaciones del ser. La desutopía es un perseguir las trazas de la potencia del ser" (...). "Lo que revela la potencia del ser es ique es plano y compacto!, lo que mide su actualidad ¡es su presencia como dado!" (...). 
"Emancipación es, por tanto, organización del infinito, declaración de la potencia humana como expresión determinada de lo indefinido. La desutopía es la forma específica de la organización del infinito" (p. 364).

Mientras que la modernidad kantiana, hegeliana e incluso marxista se basa en la utopía, es decir en todas la posibilidades de ser del Ser como telos, Spinoza, crítico profundo de la modernidad, muestra que todas las posibilidades de ser del Ser, son en la praxis o en la actualidad. Cada momento del ser, es organización del infinito. En cada especificidad de la naturaleza ya sea material o virtual, está el ser como organización del infinito.

Spinoza va en contravía de todo el pensamiento moderno por lo cual solo es leído con profundidad en las primeras décadas del siglo XX, cuando la escuela francesa de la sospecha pone en tela de juicio todo el edificio de la filosofía de la subjetividad, gracias entre otras a la fenomenología husserliana, que no encuentra diferencias entre el sujeto-yo que reflexiona y la intersubjetividad trascendental, abriendo así una puerta a la posmodernidad en el sentido de que no es posible pensar en la subjetividad sino como intersubjetividad cultural y pensarla así, es pensarla en el mundo-de-la-vida-cotidiana, y no como metafísica (Noguera, 1996).

Estas concepciones influyen en la educación en cuanto que comienza a pensarse en la contextualización de los aprendizajes, en las redes significacionales que reciben y sustentan un aprendizaje, en la construcción de diversas imágenes de los saberes gracias a las diferencias contextuales de orden ecosistémico, geográfico, climático, geológico y biológico; y de orden cultural, étnico, simbólico, expresivo y virtual. Se podría hablar, de que tendencias de la educación como la Escuela Nueva y el Constructivismo entre otras, beben de la fuente de los estudios culturales nacidos 
a su vez, de la creciente relación entre filosofía y cultura (ciencia, tecnología, arte y cotidianidad).

El hombre es influenciado en diferentes momentos de la historia por los diversos contextos de los cuales intenta resolver problemas; ello genera el tipo de conocimiento que va adquiriendo; también lo afectan los cambios en el ambiente en el cual vive y los recursos que tiene a su disposición.

Sin embargo, estas tendencias culturalistas de la educación, no logran romper los escollos epistemológicos de la escuela moderna. Son voces menores, que no logran derrumbar el imaginario de la escisión entre naturaleza y cultura. El pensamiento de Spinoza sigue marginado por ser un pensamiento de una potencia integradora que no conviene a los intereses de la economía de la globalización, figura hipermoderna de la economía capitalista.

\section{La tecnovirtualidad como expresión cultural de la expansión estética}

Las investigaciones pedagógicas realizadas en los últimos años, muestran que es posible el uso de la dimensión virtual y de las tecnologías que se aplican a la construcción de dicha dimensión, para ampliar la cobertura de las instituciones educativas en el sentido de poder llegar a más personas, a más territorios, a más etnias de un país, de un continente e incluso del planeta.

La discusión presentada en esta ponencia gira entonces alrededor de estos problemas, desde una óptica integral y holística, donde lo tecnológico y lo humanístico conforman ya una serie de pensamientos, actitudes y retos que invitan a una comprensión compleja, integral, ecológica y sistémica de dichos fenómenos. 
Los dispositivos tecnomaquínicos de la contemporaneidad, han abierto nuevas formas de historicidad; a la linealidad teleológica de la historia de los siglos XVIII, XIX y principios del XX, le ha sucedido el tejido denso de interacciones, intervalos, de líneas de fuga y de puntos fugaces de encuentro, que forman tramas caóticas de tiempos y espacios que apuntan en diferentes direcciones. Pero la técnica en la contemporaneidad no es un elemento más de nuestra cultura, sino su base. Es impensable comprender la cultura, la vida social, sin los dispositivos tecnomaquínicos. Como diría Félix Duque (1995) recordando a Heidegger (1960), el ser de la contemporaneidad es el ser de la técnica. Es la manera como es la contemporaneidad. Desde Descartes, los animales astutos "...en cuanto que su invención: el conocimiento, invierte ilusoria y catastróficamente la relación de denominación y dependencia (...) al hacer la Naturaleza un material de construcción disponible y a la mano (eso que antes llamamos "realidad") para autoproducirse como "Historia Universal" y, por ende, para erigirse en Señores de una naturaleza artificialmente capitidisminuida"... "La técnica, sería esa ficción por la naturaleza es vista -engañosamente- por el conocimiento humano como materia bruta al servicio de la historia del -hombre-" (Duque, 1995).

Tanto la visión optimista cartesiana como la pesimista heideggeriana de la técnica, obedecen a una posición de la modernidad, que es la escisión entre sujeto y objeto de conocimiento.

Estas dos visiones han influido notoriamente en las reflexiones y acciones realizadas sobre la tecnología y las humanidades.

Mientras la tecnología en la Modernidad buscó la universalidad pero desde la perspectiva de una economía de mercado y dentro de las lógicas del capitalismo, alejándose de sus propios orígenes, por cuanto la tecnología es 
una forma de la técnica y por tanto es tecné, que significó para los griegos, producción, la técnica es una expresión estética.

Todas las formas de técnicas creadas por las diversas culturas, constitutivas de las culturas, son manifestaciones de la dimensión estética de la especie humana.

La técnica es la forma como la especie humana se ha adaptado al medio. Es al mismo tiempo la manera como la especie construye formas de comunicación, formas de habitar la tierra y formas de ser (Leroi-Gourham). Cada contexto cultural ha creado sus propias formas de ser técnicas; la única cultura que ha propuesto tecnologías universales, es la cultura moderna.

Es desde esta perspectiva que estamos observando esas formas de acercamiento y de diálogo entre la tecnología y las humanidades hoy. Lo virtual es al mismo tiempo una expresión técnica de la cultura contemporánea, pero al mismo tiempo es una expresión estético-cultural.

La separación entre tecnología y humanidades ha tenido un carácter eminentemente ético-político-económico-; es un imaginario (y por ello no menos real) que ha desempeñado un papel muy importante en la escisión moderna entre mundo de la técnica y la ciencia y mundo de la imaginación la intuición y la cultura. Equivalente, repetimos, a la separación entre mundo de lo racional y mundo de lo imaginario. Sin embargo, el acercamiento, el diálogo entre la tecnología y las humanidades es cada día más urgente, puesto que en la praxis de la cultura, estas dos visiones de mundo han estado siempre juntas, por el carácter u origen estético (creativo, constructivo y autopoiésico) que tienen estas dos formas de concebir y crear el mundo.

En el momento actual, cuando el concepto de estética se ha expandido a otras creaciones culturales (entre 
ellas las tecnologías), el concepto de tecnología también ha advertido su necesaria conexión con lo creativo, a partir de relaciones mucho más densas entre el usuario de una tecnología y la tecnología misma. La densidad de estas relaciones se expresa en las artes contemporáneas que surgen precisamente de los desarrollos tecnológicos en lo que tiene que ver con la creación de mundos o naturalezas virtuales. La belleza (concepto restringido para la estética tradicional) ahora se expande hacia la tecnología, buscando que ella por sí misma, se exprese.

\section{Del espacio y el tiempo lineales, a los espacios-tiem- pos complejos a partir de la virtualidad}

Las teorías de la complejidad planteadas por Bertalanffy, Morin y Capra, entre otros, rompen con la concepción de linealidad secuencial y unívoca. La Teoría General de Sistemas (TGS) aporta una concepción compleja de las relaciones existentes entre los diversos componentes de un sistema en interacción con otros, que es la conocida frase "el todo es más que la suma de sus partes". Implica esta nueva concepción el paso de una visión mecanicista de los componentes espacio-temporales, a una visión sistemática y compleja, lo que implica, también, un cambio en las concepciones de naturaleza, cultura y realidad. Cada uno de estos eventos, tiene movimientos azarosos, no previstos y cuyas relaciones cambian, permitiendo nuevas autoorganizaciones y nuevas producciones.

La formulación de la TGS y del pensamiento basado en sus consideraciones fundamentales se da a partir de la necesidad de encontrar una disciplina que permitiera explicar las partes, estructura y comportamiento de seres vivos (individuos, sociedades y ecosistemas). El pensamiento sistémico se plantea como una forma diferente de abordar, 
ver, sentir, explicar, comprender y desarrollar el mundo, la cual considera la conectividad, las relaciones en red y el contexto, como aspectos que la diferencian de otros enfoques según lo planteado por Capra.

La complejidad sistémica de las distintas realidades, específicamente de la virtualidad, hace que surjan nuevas concepciones y eventos espacio-temporales tendientes a cero o a infinito, donde, como en el cubismo pictórico, todos los espacios y tiempos se pueden condensar en uno solo.

El hecho de que los procesos educativos se pueden realizar en un solo espacio tiempo, el virtual, a partir de espacios y tiempos diversos, geográfica y culturalmente, revoluciona los métodos y enfoques del conocimiento y de la escuela.

La virtualidad como un acontecimiento igualmente técnico como estético, ha transformado los imaginarios y prácticas culturales de nuestra contemporaneidad de manera radical. Ha puesto en el mismo escenario de un lado tecnologías de la información y de la comunicación, y de otro la diversidad cultural en toda su magnitud.

\section{Bibliografía}

Ander-Egg, Ezequiel (1999). Interdisciplinariedad en educación. Buenos Aires: Magisterio del Río de Plata.

Ángel Maya, Augusto (1998). "La razón de la vida. La filosofía Modema: Spinoza, Kant, Hegel, Marx y Nietzche". En: Cuademos Epistemología Ambiental № 4. Manizales: Instituto de Estudios Ambientales IDEA, Centro Editorial de la Universidad Nacional Sede.

Ángel Maya, Augusto (2000). La aventura de los símbolos. Una visión ambiental de la historia del pensamiento. Bogotá: Ecofondo. 
Ángel, Augusto (2001a). Platón o la pirámide invertida. Tomo II La Razón de la Vida. Medellín: IDEA Universidad Nacional de Colombia, Sede.

Ángel, Augusto (2001b). El concepto de naturaleza en Aristóteles. Tomo III La Razón de la Vida. Medellín: IDEA Universidad Nacional de Colombia, Sede.

Aristóteles (1993). De anima. Libro Tercero. Barcelona: Planeta, D'Agostini.

Betason, Gregory (1993). Espíritu y Naturaleza. Buenos Aires: Amorrortu.

Benjamín, Walter (1978). "La obra de arte en la época de la reproducción técnica", en: Escritos interrumpidos. Madrid: Taurus.

Briggs, J. y Peat, D. (1990). Espejo y Reflejo. Del caos al orden (Guia Ilustrada de la teoría del caos y de la ciencia de la totalidad). Barcelona: Gedisa.

Bozal, Valeriano (1987). Mimesis: las imágenes y las cosas. Madrid: Visor.

Calabresse (1994). La Era Neobarroca. Madrid: Ediciones Cátedra.

Capra, Fritjof (1999). La trama de la vida. Una nueva perspectiva de los sistemas vivos. Barcelona: Anagrama.

Castoriadis, Cornellius (1989). La institución imaginaria de la sociedad. Vol. 2: el imaginario social y la institución. Barcelona, Tusquest.

Castoriadis, Cornellius (1997). Ontología de la creación. Bogotá: Ensayo y Error.

Cortés, José Miguel G. (1995). Orden y Caos. Un estudio cultural sobre lo monstruoso en las artes. Barcelona: Anagrama. 
De Certeau, Michel (1996). La invención de lo cotidiano. 1. Artes de Hacer. México: Universidad Iberoamericana.

Deleuze, Gilles y Guattari, Félix (1994). Mil mesetas. Capitalismo y esquizofrenia. Valencia: Pre-textos.

Delgado, R. Manuel (1999). Ciudad liquida, ciudad interrumpida. Medellín: Colección Estéticas Expandidas, Facultad de Ciencias Humanas y Económicas de la Universidad Nacional de Colombia, Sede Medellín y Editorial Universidad de Antioquia.

Descartes, René (1980). Discurso del Método. México: Editorial Porrúa, S.A. Séptima edición.

Dorfles, Gillo (1984). El intervalo perdido. Barcelona: LUMEN.

Duque, Félix (1986). Filosofía de la técnica de la naturaleza. Madrid: Tecnos.

Duque, Félix (1995). El Mundo por de dentro. Ontotecnología de la vida cotidiana. Barcelona: Serbal.

Durand, Gilbert (1981). Las estructuras antropológicas de lo imaginario. Introducción a la arquetipología general. Madrid, Taurus.

Durand, Gilbert (2000). Lo imaginario. Barcelona: Ediciones del Bronce.

Echeverría, Javier (1994). Telépolis. Barcelona: Destino.

Echeverría, Javier (2003). Construcción de imaginarios sociales. Tesis de grado para la maestría en Estética, Universidad Nacional de Colombia, Medellín. Inédita.

Eco, Humberto (1994). La estructura ausente. Barcelona: LUMEN, $5^{\text {a }}$ edición.

Eco, Humberto (1995). Tratado de semiótica general. Barcelona: LUMEN, $5^{\text {a }}$ edición. 
Garagalza, Luis (1990). La interpretación de los símbolos. Hermenéutica y lenguaje en la filosofía actual. Barcelona: Anthropos.

Gigch, John P. van (1987). Teoría General de Sistemas. México: Editorial Trillas.

Gómez-Heras, J. M. G. (1989). El a priori del mundo de la vida. Fundamentación fenomenológica de una ética de la ciencia y de la técnica. Barcelona: Anthropos.

Heidegger, Martín (1958). La época de la imagen del mundo. Santiago de Chile: Editorial Nacimiento. Ediciones de los ANALES de la Universidad de Chile.

Heidegger, Martín (2000). Tiempo y ser. Madrid: Tecnos.

Hoyos V., Guillermo (1986). Los intereses de la vida cotidiana y las ciencias. Bogotá: Ediciones de la Universidad Nacional.

Jung, C. G. (1994). Arquetipos e inconsciente colectivo. Barcelona: Piados.

Kant, Manuel (1981). Crítica de la Razón Pura. Estética Trascendental y Analítica Trascendental. Décima edición. Buenos Aires: Losada S.A.

Leroi-Gourham, André (1971). El gesto de la palabra. Traducción de Felipe Carrera D. Venezuela: Universidad Central, Ediciones de Biblioteca, 1971.

Lévy, Pierre (1999). ¿Qué es lo virtual? Piados: Barcelona.

Lyotard, J. F. (1986). La condición Posmoderna. Madrid: Cátedra.

Maffesoli, Michel (s.f.). Elogio de la razón sensible. Una visión intuitiva del mundo contemporáneo. Barcelona - Buenos Aires - México: Paidós.

Maffesoli, Michel (1990). El tiempo de las tribus. Barcelona: Icaria. 
Malrieu (1971). La construcción de lo imaginario. Madrid: Guadarrama.

Merleau-Ponty, M. (1975). Fenomenología de la percepción. Barcelona: Península.

Mesa, Carlos (2002). "Configuraciones vernáculas de la espacialidad contemporánea". Conferencia dictada en la Universidad Nacional, Sede Manizales, Maestría en Medio Ambiente y Desartollo. Inédito.

Morin, Edgar (1994). El Método. El Conocimiento del conocimiento. Madrid: Cátedra.

Montoya, Jairo (1999). Ciudades y Memorias. Medellín: Universidad de Antioquia.

Negri, Antonio (1993). La anomalía salvaje. Ensayo sobre poder y potencia en B. Spinoza. Barcelona: Anthropos.

Noguera, Patricia (1987). "El concepto de espacio en la modernidad". En: DANA Documentos de Arquitectura Nacional y Americana № 23. Chaco: Argentina, pp. 92 a 96.

Noguera, Patricia (1993). "El paradigma tecnológico y la ética ambiental". En: Memorias Seminario y Medio Ambiental. Manizales, Universidad Nacional y SCA. Noviembre 12, pp. 45 a 52.

Noguera, Patricia (2000). Educación estética y complejidad ambiental. Manizales: Centro Editorial UN Universidad Nacional Sede.

Noguera, Patricia (2003). "El cuerpo y el mundo de la vida en la construcción de una filosofía ambiental". En: Revista Mimesis № 1 São Paulo: Universidad Estatal de Baurú. En prensa.

Ocampo, Estela (1985). Apolo y la Máscara. Barcelona: Icaria.

Ortiz-Oses Andrés, (1994). "Epidosis", en: Arquetipos y símbolos colectivos. Barcelona: Anthropos. 
Ortiz, Renato (2000). Modernidad y espacio. Benjamin en París. Bogotá: Grupo Editorial Norma.

Pardo, José Luis (1991). Sobre los espacios pintar, escribir, pensar. Barcelona: Serbal.

Platón (1958). La República o El Estado. México: Austral.

Prigogine, Ilya (1999). Las leyes del Caos. Barcelona: Crítica.

Ramírez, Luz Arabany (2003). Virtualización de los procesos e Informática Educativa: Proceso de Virtualización de la Escuela en Manizales y su impacto en el ambiente de la vida urbana. Inédito.

Ramos T., Ramón (1998). "El desvanecimiento de cronos: aspectos de la temporalidad en las sociedades actuales". En: El malestar urbano en la gran ciudad. Madrid.

Salaber, T. Pere (1995). Declives éticos, apogeo estéticos y un ensayo más. Call: Editorial Facultad de Humanidades.

Sato, Michéle (2002). "Tele-educación ambiental. Construyendo utopías". En: Revista Tópico en Educación Ambiental Volumen 2. № 4. México: UNAM.

Scaf, Adamm (1992). A sociedade informática. São Paulo: Editora Brasilense UNESP.

Serres, Michel (1985). Los cinco sentidos. Filosofía de los cuerpos mezclados. París: Bemard Graseet.

Serres, Michel (2001). Lo virtual es la misma came del hombre. Paris: Le Monde.

Silvio, José (2000). La virtualización de la universidad, ¿cómo podemos transformar la educación superior en la tecnología? Caracas: IESALC / UNESCO.

Spinoza, B. (1975). Ethica. Alianza Editorial. 
Steiner, George (1991). En el Castillo de Barba Azul. Aproximaciones a un nuevo concepto de Cultura. Barcelona: Gedisa.

Vattino, Gianni (1985). El fin de la Modernidad. Barcelona: Gedisa.

Vilar, Sergio (1997). La nueva realidad comprender la complejidad con métodos transdisciplinarios. Barcelona: Kairós.

Xibille M., Jaime (1998). "La semiosis espacial de la ciudad maquínica" en: Metrópolis: Espacio, Tiempo y Cultura. Medellín: Revista de la Facultad de Ciencias Humanas de la Universidad. 